\title{
Content in context: analyzing interactions in a graduate-level academic Facebook group
}

\author{
Deborah Moore-Russo ${ }^{\dagger}$, Michael Radosta ${ }^{* \dagger}$ (D, Kristi Martin and Sara Hamilton
}

* Correspondence:
mradosta@buffalo.edu
${ }^{\dagger}$ Equal contributors
University at Buffalo - The State
University of New York, Buffalo, USA

\section{Springer Open}

\begin{abstract}
This case study investigated a Facebook group created and managed by a faculty administrator for students and alumni in a graduate-level education program. While most research to date has considered course-based applications, this research reports on how an academic Facebook group functioned as a way to interact with students, alumni, and faculty outside of a formal academic context. Borrowing methods from studies in market research, the researchers analyzed posts and user interactions on the group's page over the course of 1 year. Posts were inductively coded into thematic categories, such as humor, student photos, and academic readings, and coded again by their mode of consumption, such as text, image, and hyperlinks. Using regression analysis, the categories and modality of posts were tested for their relationship to user interactions, which included likes, comments, and shares. Additionally, users were tallied on their frequency of interactions, and how that related to the categories of posts. Despite a large proportion of academic readings via hyperlinks, results found significantly more interactions for text and image-based posts pertaining to locally situated interests and entertaining content. This behavior was moderated by how frequently a user participated, with frequent users interacting more than expected with university notices. The results support previous research citing Facebook as primarily a means of entertainment and socialization, but with a clear advantage for student-centered content. The implication is that Facebook groups have potential in higher education contexts beyond entertainment when it's used to support and recognize social connections among students.
\end{abstract}

\section{Introduction}

Facebook is the market leader in social networking services (SNSs), with nearly 1 billion average daily users worldwide, and over 160 million users in North America alone (Facebook, 2016). Having begun as an SNS for college students in 2004 (Boyd \& Ellison, 2010), Facebook has emerged as the digital point of contact for $80 \%$ of online Americans, including a vast majority of college students (Greenwood, Perrin, \& Duggan, 2016). Internationally, Facebook is also the most popular choice, if not as much in the U.S. (Saw, Abbott, Donaghey, \& McDonald, 2013). One major appeal to college students is how it allows them to communicate and maintain connections with people who share their interests without needing to be face-to-face. (Echenique, Molías, \& Bullen, 2015).

(c) The Author(s). 2017 Open Access This article is distributed under the terms of the Creative Commons Attribution 4.0 International License (http://creativecommons.org/licenses/by/4.0/), which permits unrestricted use, distribution, and reproduction in any medium, provided you give appropriate credit to the original author(s) and the source, provide a link to the Creative Commons license, and indicate if changes were made. 
Since its inception, it has elicited research interest as a tool to support learning and student interaction (Mason, 2006; Selwyn, 2007), but also as a distraction and enabler of negative social behavior in education (Bugeja, 2006; Junco, 2012; Kirschner \& Karpinski, 2010). The potential of the SNS is obvious; it is an overwhelmingly popular social medium, rich in textual, graphical, audiovisual, and interactive content accessed from any internet-connected device. It also has low technical requirements, which make it an easy platform for an instructor or faculty advisor to leverage when trying to expand the capacity for students to communicate and collaborate with their peers, faculty, and others in their institutions. As a pervasive an open social network, however, it also presents challenges. Facebook is a highly competitive information space, where entertainment, commerce, games, and non-academic interests vie for a student's (and everyone else's) attention. On Facebook, a post from an instructor, advisor, or department is but one of many events in a student's feed, easily missed or ignored in favor of countless other posts which the user chooses to interact with. Research is needed to further explore how Facebook might serve academic engagement (Siemens \& Weller, 2011). While there is little promise that Facebook might increase students' GPAs (Manca \& Ranieri, 2013), its role as a popular platform could allow academic communication and collaboration among students and with their faculty in important ways. As Tinto (1975) argued, there is more to college completion than just getting good grades. Students also need a sense of social connection to their college peers, faculty, and ultimately, the institution. The question remains as to how Facebook can serve academia in ways that play on its many strengths, while avoiding ill-conceived applications that could contravene the reasons so many students use the SNS. Answers require consideration of more fundamental investigations about how Facebook functions as a successful social network, and how the capabilities, norms, and behaviors associated with this digital platform might serve particular higher education purposes.

\section{Research on Facebook in higher education}

Social science research on Facebook has focused mostly among five dimensions: 1) who uses Facebook, 2) why people use it, 3) how users present themselves, 4) how users interact, and 5) users' attitudes about privacy (Wilson, Gosling, \& Graham, 2012). Within educational contexts, a considerable amount of research has looked at survey data about who uses SNSs, how students and instructors feel about using them, for what purposes they are used, and the effects of their use (Hew, 2011). Historically, the academic use of SNSs has remained stubbornly infrequent, as students are hesitant to have formal academics invade an otherwise personal space (Madge, Meek, Wellens, \& Hooley, 2009; Gettman \& Cortijo, 2015). Also, few instructors have expressed interest in using Facebook in their courses, and, even when there were opportunities for incorporating SNSs, students reported little to no use for academic purposes (Roblyer, McDaniel, Webb, Herman, \& Witty, 2010). However, as more students use the network more frequently, the interest in using it for coursework seems to be growing (Lim \& Richardson, 2016). Among professors, the pattern appears to be similar; a growing number of proponents use Facebook personally and appreciate the SNS's potential power to build professional relationships with students (Sarapin \& Morris, 2015). 
Comparatively fewer studies have observed specific applications and how participants interacted, which could inform appropriate uses of the SNS. One factor that is becoming apparent is that the medium matters. External hyperlinks typically receive the least attention compared to images (Valerio, Herrera-Murillo, VillanuevaPuente, Herrera-Murillo, \& del Carmen Rodríguez-Martínez, 2015). Another factor is the content-in-context. Looking at a Facebook group for a college-level course, Bowman and Akcaoglu (2014) analyzed the activity to identify categories of posts and looked for related patterns of interactions among users. The most common categories for posts and interactions were utilitarian in the form of exam review and class-administrative questions and answers. The students paid less attention to more discursive interactions about course material. The other important finding was that user involvement was asymmetrical. The dispersion showed that there were a number of "super-users" skewing the results with most participants providing a much smaller number of posts and comments. This pattern of many readers and few contributors is considered typical of social networks, and has been dubbed the "1\% rule" (Arthur, 2006) and has been sustained in more recent research (van Mierlo, 2014). Yet, despite this asymmetry, Bowman and Ackaoglu found that the students in the Facebook group had better scores and engagement with the course materials than non-users overall, suggesting a benefit of association with even passive participation.

\section{Facebook's relevant features and functions}

Three core aspects of Facebook are germane to this study: posts, groups, and interactions.

Posts

The primary content of Facebook is an updating feed of posts. Posts are short, bounded digital artifacts created by the user, their friends, their groups, and pages generated by content providers. The most common modalities used in posts are brief passages of text, images, web-links, and videos. Facebook's servers compile posts with advertising to generate a customized feed for each user based on their network affiliations.

\section{Interactions}

Facebook users interact with posts in several ways. The most popular and easiest to use is the "like" button, introduced in 2009 (Kincaid, 2009). Anyone who can see the post can see how many likes a post receives and who liked the post. In addition to liking, users can make comments to posts and can reply to other comments, potentially including images and web links. Comments also have like buttons, independent of the post's likes. Often, when a user likes or comments on posts and other comments in their feed, Facebook shares this activity with friends in their network. Finally, when users wish to share a post in their feed, they can press the share button, sending it to their timeline and their friends' newsfeeds. Like any other post, a shared post can receive likes and comments as a shared event. Since these events are shared with friends, it is possible for posts to become "viral" where likes, comments, and shares multiply exponentially as a critical mass of people view and interact with the post. 
Groups

This study involves a special kind of Facebook profile, a Facebook Group. Groups are user-administered Facebook entities that can generate posts to their own timelines and the feeds of the groups' members. One or more registered Facebook users serve as the administrator for the group, and the group can be public (i.e., shared with all) or private (i.e., shared with only a select group of users having access). Group members can click on the group page to see the latest updates; they also receive updates from the group administrator in the feeds on their personal pages. Other group members will know when a post receives likes or comments by their peers. Administrators can select settings that allow members to post directly to the group page. These combined set of features make Facebook groups an enticing option for those in higher education who wish to engage and foster interaction among a specific network of students (e.g., Bowman \& Akcaoglu, 2014; Cuesta, Eklund, Rydin, \& Witt, 2015).

\section{Theoretical framework}

The principal assumption for this investigation is that likes, comments, and shares for posts offer a way to measure engagement (Valerio et al., 2015). Cvijikj and Michahelles (2013) analyzed the engagement in Facebook groups by observing the content and medium in relation to the available interactions. In their study of major food retailers, they hypothesized and concluded that the categorical nature of the post (entertainment, information, promotions, and other) and the medium of the post (i.e., photo, hyperlink, text, and video) had a significant relationship to how users responded. For example, they found entertaining posts and photos to receive the most attention, and promotions and hyperlinks to receive the least. For the academic context of this study, we examine and reconstruct the categorical nature of posts to suit the non-commercial context of the group.

For the academic context, this study also considers Van der Heijden's (2004) hedonic, pleasure-oriented extension of the Technology Acceptance Model (TAM) (Davis, 1985, 1989; Davis, Bagozzi, \& Warshaw, 1989; Venkatesh \& Davis, 2000). The basic TAM argued that two dimensions drive the adoption of educational technologies: 1) its perceived ease-of-use, and 2) usefulness. However, van der Heijden hypothesized that perceived enjoyment was an emerging factor for adopting developing applications, including videogames, web browsing, and social media. Sledgianowski and Kulviwat (2009) tested this theory with SNSs and found that playfulness (perceived enjoyment) was the strongest predictor of the intention to use SNSs, and directly predicted its actual use. The only other factor that was important was the service's "critical mass" or popularity with other users, which Facebook had achieved. This theory allows a discussion about how we would expect members of Facebook group to interact in relationship to the content and type of posts.

The study examines at the posts and interactions of an academic Facebook social group to answer the following questions.

1. When posts are coded into thematic categories, how do these categories relate to the quantity of interactions?

2. When posts are coded by the principal mode of interaction, how do these modes relate to the quantity of interactions? 
3. How to the thematic categories relate to users who differ in their frequency of interactions?

\section{Methods}

This case study examines activity in a public Facebook group whose intended members were students in and alumni from a graduate mathematics education (math ed) program at a U.S. university. The program director served as the administrator for the Facebook group page with help from other math ed faculty, producing most of the posting content and occasionally forwarding posts of group members. The Facebook group used the identity and voice of the university math ed program, with posts unsigned by the principal administrator. According to the administrator, posting to the group was non-experimental and driven by two practical purposes: (a) offering a platform to share information and opportunities with all students and alumni of the program in a relatively easy manner and (b) creating a sense of communal identity with the use of humor and quotes relevant to those in mathematics education. No posts involved coursework. As such, the collective themes and ideas were idiomatic of the math ed program and its director, and no formal goals for the Facebook page were defined beyond using the medium for social interaction and the equitable sharing of information. Therefore, the purpose of this study's methodology is to investigate how the members responded and interacted in this context, which had the dual intentions of being socially entertaining, but also informative and connecting for its members.

\section{Participants}

Prior to the time of the study, the department invited students and alumni to join the group. The group was public, with most enrolled members affiliated with the program at the university as students $(58 \%)$ or alumni $(22 \%)$. Most of the other users were students and alumni in other programs (usually in science education), math ed faculty, or other faculty either in the same department or school as the math ed program. Individuals' participation was voluntary and had no connection to their coursework or degree requirements. Overall, 74 members joined and participated in the group, with $56 \%$ female, and $44 \%$ males participating. Age, when available, was grouped into brackets of those in their 20s (40\%), 30s (30\%), and those 40 and over (30\%). The demographic participation did not differ in any meaningful way from the departmental enrollment.

\section{Data sources and collection}

A 1-year period of group activity was selected for the study. For the purposes of understanding how the group interacted with different posts and how that group varied, the Facebook group page provided ample quantitative and qualitative data. Its constraints as a medium of interaction afforded three salient units of analysis: Facebook posts, Facebook profiles of the group members, and their interactions. The feed of posts to the group page was converted to a searchable archive, and a spreadsheet was created to uniquely identify each post, the user who posted or provided the post content, as well as the type and frequency of interactions. 


\section{Data analysis}

Quantitatively, each post had a total number of interactions, comprised of a quantity of likes, comments, liking-of-comments (comment-likes), shares, and liking-of-shares (share-likes). Additionally, Facebook provided the number of users reached (reach), which is a tally of how many people could have seen the post in the feed, which can include friends-of-friends and non-members. Qualitatively, posts were further examined to see what kinds of content they contained and in what context. Taken together, the expectation was that a pattern of interaction would emerge about different post contexts and levels of user interaction. By the end of the study period, 243 posts to the group page were logged, with 201 posts generated directly by the faculty administrator and 42 from members. In 1 year, 75 identified group members interacted with the group at some point during the observation through likes, comments, or shares; in addition, 26 friends outside of the group interacted through shares and Facebook's automated post sharing to friends of friends.

Consistent with the research questions, posts were coded twice for the principal mode of interaction and their thematic content. Users were tabulated by the their interactions with posts per given category. Expecting thematic content to relate to the response it received from the group, posts were examined for emerging themes through a general inductive approach and emergent design. Following this method, two members of the research team began without any preconceived structures allowing categories to emerge from the data. The researchers utilized these categories to make sense of observed activity or phenomena (Thomas, 2006). The system of categories based on thematic content was determined when two members from the research team reviewed all of the posts independently and then revisited all the posts together repeatedly (at least three times per post). During this period, the team used their notes and discussion from their individual readings and reviewed the posts to revise, collapse, reform, and eventually agree on 11 categories as representing the data. The joint review of all posts was repeated until no new categories or subcategories were identified. The objective was to insure that the categories represented the data to the point of saturation where no relevant or new insights emerged from considering the categorical nature of the posts (Bryman, 2001).

To learn if these coding categorizations related significantly to the number of interactions, the data were analyzed with linear regression methods using the SPSS statistical software package. In addition to using posts as the units for analyses in stages one and two when considering interactions, the users were taken as the units of analyses in stage three where their data were analyzed to look for possible gender and age-group differences in interaction frequency.

\section{Findings}

To address the first research question, the frequencies of posts and user interactions by thematic content are displayed in Table 1. The number of posts is outlined in terms of the three broad thematic categories.

Professional information posts were the most common type on the group page, comprising 113 (45\%) of all posts in the year under study. Reading posts, which accounted for over half of the professional information posts, often contained links to external websites, with a brief note from the administrator asking users to browse to an 
Table 1 Number of posts and users reached by Thematic content categories

\begin{tabular}{|c|c|c|c|c|}
\hline $\begin{array}{l}\text { Broad } \\
\text { category }\end{array}$ & $\begin{array}{l}\text { Refined } \\
\text { subcategory } \\
\text { (Abbreviation) }\end{array}$ & Category definition & $\begin{array}{l}\text { Number } \\
\text { of posts }\end{array}$ & $\begin{array}{l}\text { Users } \\
\text { reached }\end{array}$ \\
\hline \multirow[t]{3}{*}{$\begin{array}{l}\text { Professional } \\
\text { Information }\end{array}$} & Reading (Rdg) & $\begin{array}{l}\text { A news item, web post, or article about relevant } \\
\text { topics intended to disseminate either research } \\
\text { implications or state policy issues/revisions }\end{array}$ & $64(25 \%)$ & $4730(25 \%)$ \\
\hline & Opportunity (Opp) & $\begin{array}{l}\text { Employment opportunities related to math ed } \\
\text { (e.g., tutoring or K- } 12 / \text { higher ed employment) or } \\
\text { funding opportunities }\end{array}$ & $31(12 \%)$ & $1571(8 \%)$ \\
\hline & Resource (Res) & $\begin{array}{l}\text { General educational and career resources } \\
\text { (e.g., new math app, teaching materials) }\end{array}$ & $18(7 \%)$ & $1146(6 \%)$ \\
\hline \multirow[t]{3}{*}{ Entertainment } & Humor (Humor) & $\begin{array}{l}\text { Math- or education-related jokes or observations } \\
\text { intended to entertain }\end{array}$ & $59(23 \%)$ & $4972(26 \%)$ \\
\hline & Quote (Quote) & $\begin{array}{l}\text { A direct, inspirational quote from an author or } \\
\text { historical figure, usually related to math, teaching, } \\
\text { or learning }\end{array}$ & $16(6 \%)$ & $864(5 \%)$ \\
\hline & Problem (Prob) & $\begin{array}{l}\text { Math problem posed to the group, as an } \\
\text { intellectually stimulating challenge }\end{array}$ & $3(1 \%)$ & $122(1 \%)$ \\
\hline \multirow{5}{*}{$\begin{array}{l}\text { Locally } \\
\text { Situated } \\
\text { Information }\end{array}$} & Event (Evnt) & $\begin{array}{l}\text { Information, usually involving the date/time/location } \\
\text { regarding a departmental or other math ed event }\end{array}$ & $23(9 \%)$ & $2295(12 \%)$ \\
\hline & Photo (Photo) & $\begin{array}{l}\text { Photo(s) involving faculty, students or alumni, often } \\
\text { taken at a departmental or other math ed event }\end{array}$ & $15(6 \%)$ & $1883(10 \%)$ \\
\hline & Notice (Ntce) & $\begin{array}{l}\text { Notices or general information about university affairs } \\
\text { (e.g., academic deadlines and course schedules) }\end{array}$ & $10(4 \%)$ & $1052(5 \%)$ \\
\hline & Kudos (Kudos) & $\begin{array}{l}\text { Announcement of student, alumni, or faculty } \\
\text { achievement or life event }\end{array}$ & $7(3 \%)$ & $366(2 \%)$ \\
\hline & Request (Req) & $\begin{array}{l}\text { Request of assistance from math ed group related } \\
\text { to local issue or request for photos/posts from } \\
\text { administrator }\end{array}$ & $6(2 \%)$ & $170(1 \%)$ \\
\hline
\end{tabular}

article or website. Readings were typically more professionally oriented and covered topics such as education reform, incorporation of technology in education, standardized testing, and mathematical theory. Opportunity posts primarily related to either full-time or part-time employment or other opportunities (e.g., external funding for teachers). Resource posts usually contained hyperlinks to virtual manipulatives, pdf files of puzzles, worksheets, or other teaching resources that could be used in the classroom.

Entertainment posts, which aimed to amuse or bring enjoyment, were next most common, comprising 78 (31\%) of all posts. The humor posts accounted for 59 (23\%) of all posts in the study. Most humor posts were images (e.g., either cartoons or memes) with captions and were typically related to either math or teaching. Some posts were shared by members, but most came from the faculty administrator. The quote posts were usually short text references intended to be inspirational quotes for aspiring teachers. The problem posts were mathematical problems posed as fun challenges to the group.

The locally situated posts included event, photo, notice, kudos, and request posts. These comprised 61 or $24 \%$ of all posts. Event posts accounted for over a third of the posts in this category. Many of the event posts were invitations and updates about a regular math ed game night activity in which a sizable number of students and alumni participate; others were related to other happenings such as dissertation defenses and regional conferences. The photo posts involved faculty, students or alumni, often taken 
at a departmental or other math ed event (e.g., graduation photos of math ed students). Notice posts contained practical information relevant to students regarding university affairs (e.g., academic deadlines). The kudos posts celebrated students', alumni's, and faculty's accomplishments and milestones in life (e.g., new employment, engagement announcement). The request posts were either from the administrator for users to make posts or send in photos, or these requests were related to issues or needs of math ed students and alumni (e.g., a doctoral student requesting someone to help with coding data).

Facebook's algorithms ultimately determined how many people saw the posts beyond the group members. The last column in Table 1 provides information regarding how many total users received the post in their feeds. Even though there were more professional information posts than entertainment posts or locally situated posts, they did not have the same reach. Locally situated posts, which accounted for $24 \%$ of all posts, accounted for $30 \%$ of the users reached. The entertainment posts accounted for $31 \%$ of all posts and accounted for $31 \%$ of all users reached. Professional information posts had smaller percentage of users reached (39\%) as compared to the number of posts made (45\%).

Some of the subcategories had higher percentages of users reached (reach) than the number of posts. This was the case for photo (10\% reach, 6\% of posts), humor (26\% reach, $23 \%$ of posts), and event (12\% reach, $9 \%$ of posts) posts. Opportunity posts were the only subcategory that reached users at noticeably lower percentage $(8 \%)$ that the percentage of posts made (12\%).

Over the year in which data was collected, the group had 920 Facebook interactions, including 678 likes, 194 comments, 29 comment-likes, 10 shares, and 9 share-likes. The distribution of total interactions was positively skewed, $2.76(S E=0.15)$, with 75\% of the posts having fewer than the mean of 3.64 interactions $(S D=5.41)$, and $30 \%$ of the posts receiving zero interactions. Meanwhile, $10 \%$ of posts accounted for nearly $30 \%$ of the total interactions. This distribution is examined in the final section.

Figure 1 displays the proportion of posts to the proportion of (all) interactions (including likes and comments), by subcategory. The humor, event, photo, kudos, and notice categories had larger proportions of interactions than their numbers of posts. Humor posts had the most interactions and likes overall. Event posts had the most comments, as members were often stating their attendance, sending in regrets (at not being able to attend), planning specifics for the event (e.g., organizing snacks), and discussing previous activities.

Interestingly, there was one post to the group page that went viral. The post, which was sent out on a particularly snowy day, depicted a humorous meme about winter weather in the Northeast and reached nearly 20,000 users, and generated over 400 interactions. This post was marked as an outlier, and removed from the analysis.

Linear regression was performed to determine if the effect of the posting category on the total number of interactions was significant and to identify which categories of posts generated the most interactions. Categories were entered simultaneously, with readings selected as the intercept, or control category, due to their high proportion of posts, and to compare the effect of the academically oriented postings to the more entertainment and socially oriented posts typical of Facebook. The summary of the model is shown in Table 2 . 


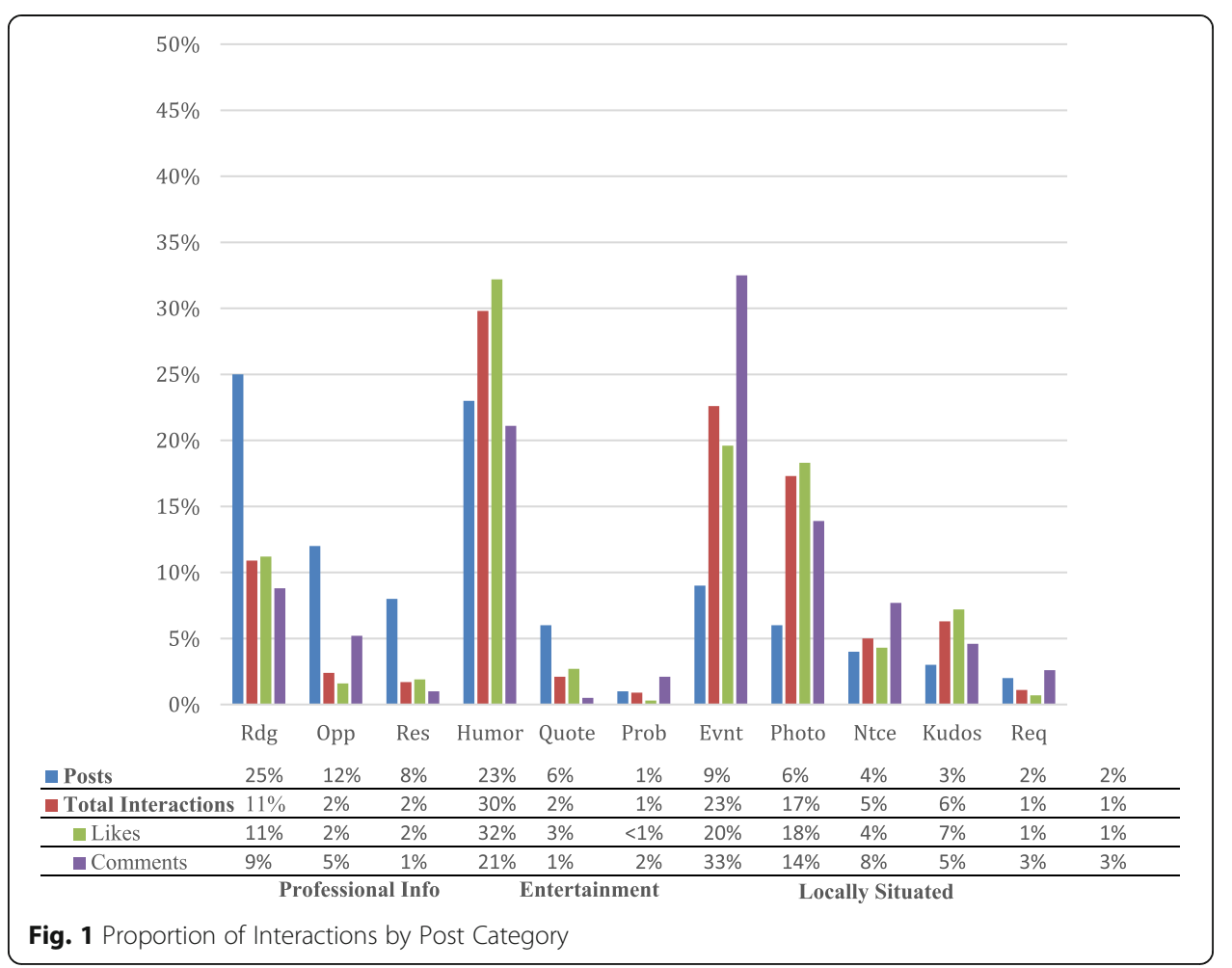

The humor, event, photo, notice, and kudos posts were significantly associated with more interactions than other categories. Event and photo posts were particularly active categories with more than twice as many interactions per post as even humor or kudos posts. The $R^{2}$ of category was .33 with entertainment and locally situated categories having the strongest relationship with interactions.

\section{Interactions as related to posts' principal modes of interaction}

To examine the second research question regarding ease-of-use, posts were coded by the principal mode of interaction required on the part of the user. The modes of interaction were classified into two broad categories: self-contained (i.e., text, image and video) or external reference (i.e., hyperlinked).

Table 2 Regression of the number of interactions by Post category

\begin{tabular}{llllc}
\hline & Variable & $b$ & SE b & $t$ \\
\hline Professional Information & Opportunity & -0.85 & 0.99 & -0.86 \\
& Resource & -0.72 & 1.18 & -0.61 \\
Entertainment & Humor & 3.08 & 0.82 & $3.78^{* * *}$ \\
& Quote & -0.38 & 1.26 & -0.30 \\
Locally Situated Information & Problem & 1.10 & 2.67 & 0.41 \\
& Event & 7.48 & 1.10 & $6.81^{* * *}$ \\
& Photo & 9.04 & 1.30 & $6.97^{* * *}$ \\
& Notice & 3.03 & 1.54 & $1.98^{*}$ \\
& Kudos & 6.72 & 1.80 & $3.74^{* * *}$ \\
& Request & 0.10 & 1.93 & 0.05 \\
\hline
\end{tabular}

${ }^{*} p<.05 ;{ }^{* *} p<.01 ;{ }^{* * *} p<.001 . R^{2}=.33, F(10,242)=11.91$ 
Table 3 outlines the frequency for the modes of interaction. In some instances, the mode of the post corresponded to certain thematic content categories for posts. For example, quote, event, and notice posts were almost exclusively self-contained posts that contained only text. Other posts, such as photos, were image driven, although they may have had brief supplementary text. Humor posts fell primarily in the self-contained category with jokes that were completely self-contained text or cartoons that were primarily visual images with limited supplementary text. Some included embedded videos posted.

The external reference posts all contained links to other websites. These hyperlink posts may have included images and text, but the intention was for a guest to click and read or watch content on a third party site off the Facebook group page. This was often the case for reading and resource posts. These hyperlink posts were the most common post mode; they typically linked to more lengthy written content. It was expected they would be less easy-to-use than the self-contained posts.

The proportion of interactions by mode are in Fig. 2. Self-contained posts had more total interactions (84\%) and hence reached more users (63\% of users reached) compared to their number (57\% of all posts) than posts that hyperlinked to external references (44\% of posts, $37 \%$ reach, $16 \%$ of interactions). Images, which accounted for only $18 \%$ of the posts received substantially more interactions overall, including $60 \%$ of the likes. Text posts (36\%), however, received a substantial proportion of comments (45\%).

Table 4 shows the linear regression results of mode to total interactions. Text, image, and video posts were entered simultaneously into the model. Hyperlink posts were chosen as the control, because they were the most common kind of post and were expected to be the least easy-to-use compared to content that can be viewed and evaluated within the Facebook feed.

Image and text posts had significantly more interactions than hyperlink or video posts. A possible reason may be that embedded video are similar to hyperlink posts in that they also require more time to interact with than a text or image post.

It is important to note that in a Fisher's Exact test, modality was highly associated with category, $p<.001$. Reading posts were almost always hyperlink posts, while posts categorized as humor were frequently image posts. The locally situated categories were typically text- or image-based, therefore significance was expected for these modes. Comparing the two models, the adjusted $R^{2}$ of modality (.20) was less than that of category (.30), implying that the context of a post explains more of the variance than the mode's ease-of-use for interactions. For example, posts coded in the photo thematic category were always coded as an image, and many popular humor posts were images, yielding an overlapping effect

Table 3 Number of posts and users reached by Principal mode of interaction

\begin{tabular}{|c|c|c|c|c|}
\hline Type of post & $\begin{array}{l}\text { Principal mode } \\
\text { of interaction }\end{array}$ & Definition & $\begin{array}{l}\text { Number } \\
\text { of posts }\end{array}$ & $\begin{array}{l}\text { Users } \\
\text { reached }\end{array}$ \\
\hline External Reference & Hyperlink & $\begin{array}{l}\text { Post was a link to external content captioned } \\
\text { with headline text and/or images }\end{array}$ & $101(44 \%)$ & $6892(37 \%)$ \\
\hline \multirow[t]{3}{*}{ Self-contained } & Text & $\begin{array}{l}\text { Post included self-contained text whose } \\
\text { meaning was determined through reading }\end{array}$ & 81 (36\%) & 5788 (31\%) \\
\hline & Image & $\begin{array}{l}\text { Post included an image (sometimes with } \\
\text { captions or text) whose meaning was } \\
\text { primarily embedded in viewing the image }\end{array}$ & $40(18 \%)$ & $5669(30 \%)$ \\
\hline & Video & $\begin{array}{l}\text { Post was an embedded video that played } \\
\text { directly in the Facebook application }\end{array}$ & $6(3 \%)$ & $350(2 \%)$ \\
\hline
\end{tabular}




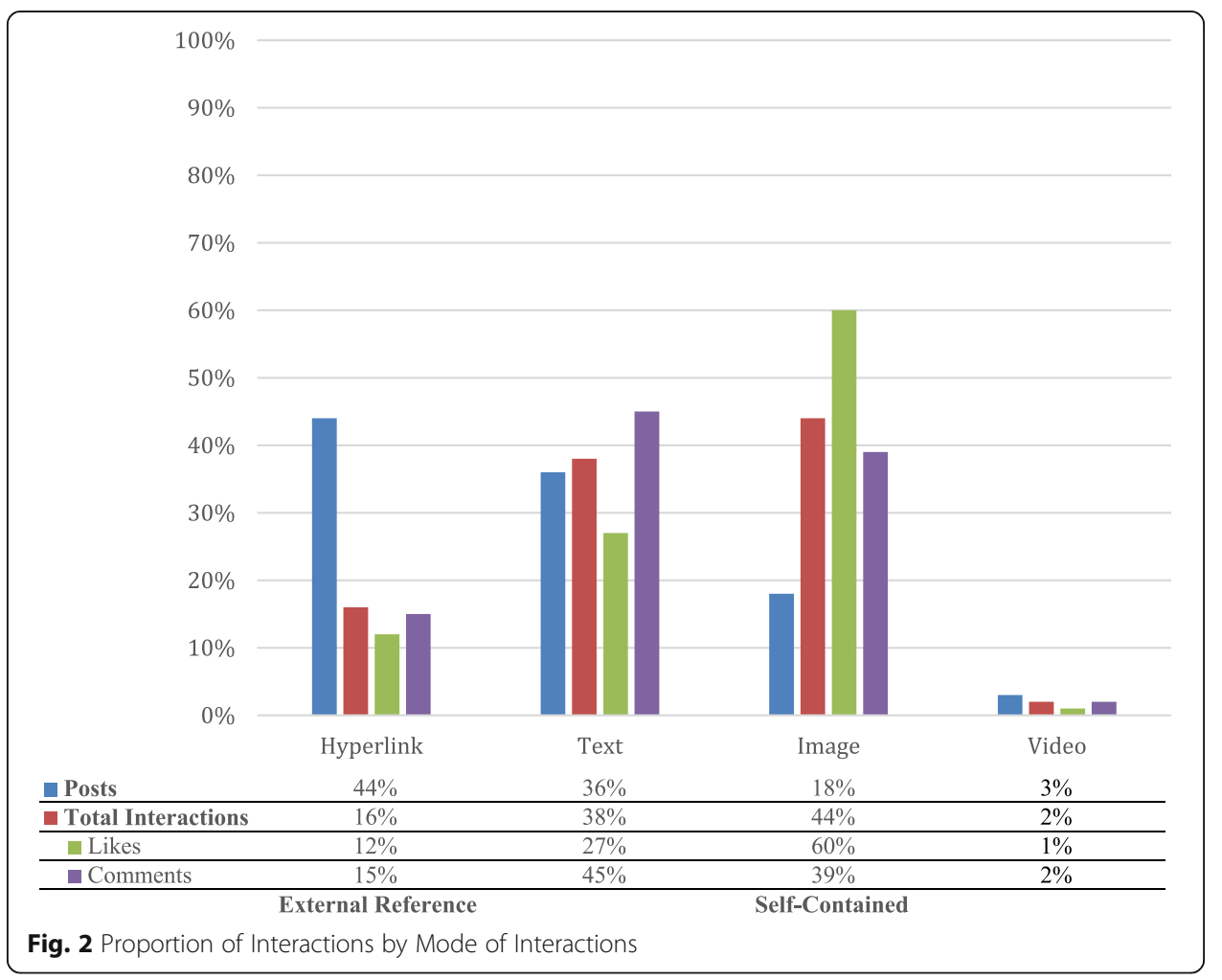

for the predictive power of images. Yet, photos of group members received considerably more interactions per post than humor posts with photos, suggesting that content (or context) was king, and more precise in predicting interactions.

\section{User interactions by category}

Users and their interactions were logged by post, and, if available, included the gender and age group. The faculty administrator interacted substantially with the group, so the administrator's interaction data were excluded examine user behavior of 75 distinct users. The average number of interactions by user varied greatly and was positively skewed, $M=9.92$, $S D=11.57$, skewness $=1.98(S E=.28)$. This skewed distribution is illustrated in Fig. 3.

The distribution of interactions were divided into quartiles, yielding four logical groups of user interaction. These include low users $(n=38,51 \%), M=2.45, S D=1.01$, range $1-5$, medium users $(n=14,19 \%), M=8.29, S D=1.01$, range 6-10, high users ( $n=14,19 \%), M=14.71, S D=4.43$, range $11-25$, and super users $(n=9,12 \%), M=36.56$, $S D=9.54$, range 26-52. In this breakdown, nearly half of the members (all of those in the

Table 4 Regression of number of interactions to posts' mode of interaction

\begin{tabular}{llll}
\hline Variable & $b$ & SE $b$ & $t$ \\
\hline Text & 0.368 & 0.13 & $2.88^{* *}$ \\
Image & 1.39 & 0.16 & $7.94^{* * *}$ \\
Video & 0.11 & 0.38 & 0.30 \\
\hline
\end{tabular}

${ }^{*} p<.05 ;{ }^{* *} p<.01 ;{ }^{* * *} p<.001 . R^{2}=.20, F(3,249)=21.17, p<.001$ 


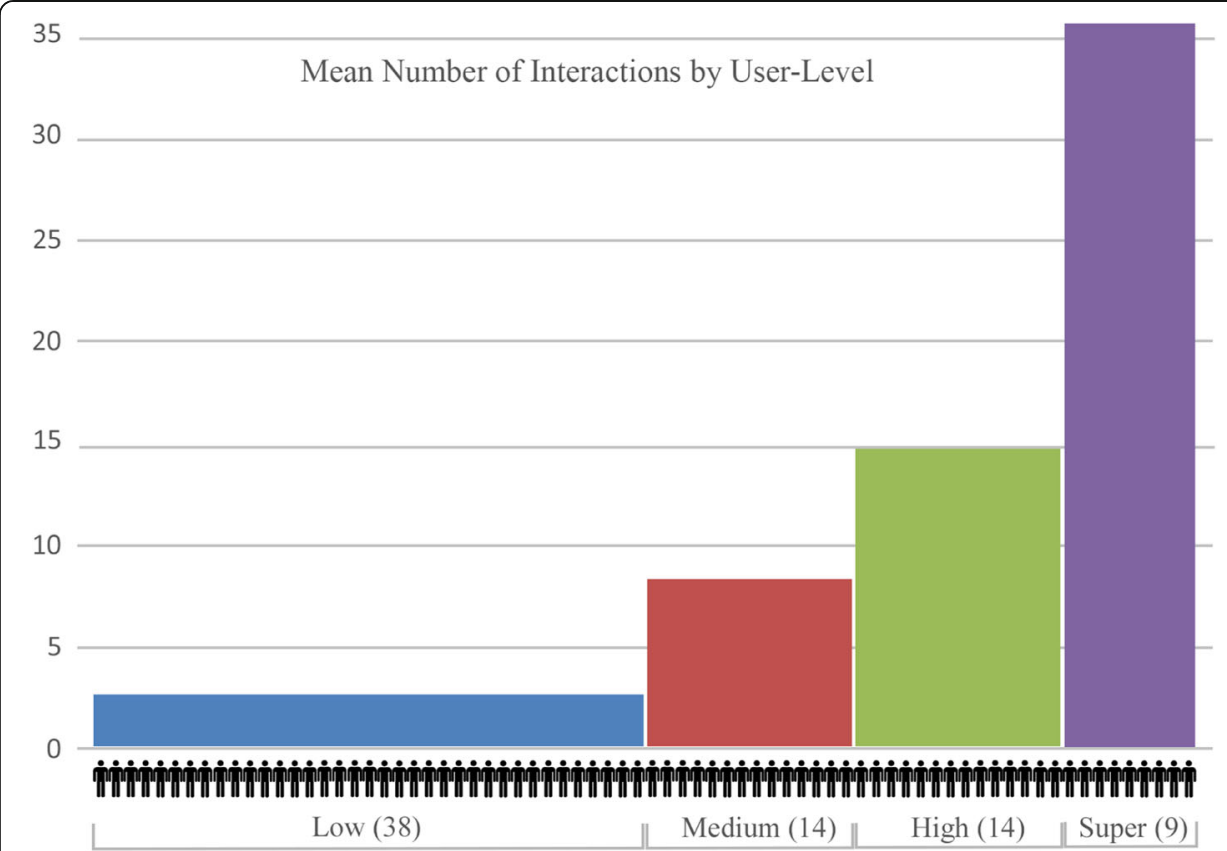

Fig. 3 Area plot of number of Users by Mean Interactions per User-Level

Low user group) contributed five or fewer interactions each. On the other end, the nine Super users (12\%) accounted for over $44 \%$ of the total interactions.

To find out if the pattern of interactions were consistent across categories for each user-level, a chi-square test was performed. Table 5 shows the percentage of each userlevel on a category and the total categorical interactions for the identified users only. (Note that this is different from the overall interactions by post presented above where all anonymous user data were included.)

The result was significant, $\chi^{2}(30)=93.1, p<.001$, indicating that certain categories were associated more with different user-levels. Looking at the standardized residuals of each cell and setting a significance of $p<.01,(z= \pm 2.58)$, it was found that low users were significantly more likely to interact with kudos $(z=4.26)$, and less with university notices $(z=-3.48)$, suggesting that they were most interested in celebrating their peers and least responsive to university information. The medium users were also less interested in notices $(z=-2.98)$, and their increase in interactions is most attributable to postings for events $(z=2.87)$ compared to other groups. High users were far more interested in resources $(z=3.38)$ than expected, and super users were interacting considerably more with

Table 5 Percentages of category interactions per user-level

\begin{tabular}{|c|c|c|c|c|c|c|c|c|c|c|c|}
\hline \multirow[t]{2}{*}{ Group } & \multicolumn{3}{|c|}{ Professional Information } & \multicolumn{3}{|c|}{ Entertainment } & \multicolumn{5}{|c|}{ Locally Situated } \\
\hline & $\mathrm{Rdg}$ & Opp & Res & Humor & Quote & Prob & Evnt & Photo & Ntce & Kudo & Req \\
\hline All & $7.0 \%$ & $4.1 \%$ & $3 \%$ & $33 \%$ & $2.3 \%$ & $1 \%$ & $4.4 \%$ & $13 \%$ & $26.8 \%$ & $3 \%$ & $2 \%$ \\
\hline Low & $7.5 \%$ & $4.3 \%$ & $1.1 \%$ & $34.4 \%$ & $2.2 \%$ & $0 \%$ & $7.5 \%$ & $18.3 \%$ & $11.8 \%^{\mathrm{a}}$ & $9.7 \%^{\mathrm{a}}$ & $3.2 \%$ \\
\hline Medium & $12.9 \%$ & $7.8 \%$ & $2.6 \%$ & $27.6 \%$ & $2.6 \%$ & $0 \%$ & $9.5 \%^{\mathrm{a}}$ & $12.9 \%$ & $15.5 \%^{\mathrm{a}}$ & $4.3 \%$ & $4.3 \%$ \\
\hline High & $6.9 \%$ & $4.4 \%$ & $6.4 \%^{\mathrm{a}}$ & $32.8 \%$ & $2.5 \%$ & $1.5 \%$ & $4.9 \%$ & $11.8 \%$ & $26.0 \%$ & $1.0 \%$ & $2.0 \%$ \\
\hline Super & $4.8 \%$ & $2.7 \%$ & $1.5 \%$ & $34.5 \%$ & $2.1 \%$ & $1.2 \%$ & $1.5 \%$ & $13.0 \%$ & $35.5 \%^{\mathrm{a}}$ & $1.5 \%$ & $1.5 \%$ \\
\hline
\end{tabular}

${ }^{a}$ Significant interactions with that category above or below expected values at the .01 probability level 
university notices $(z=4.77)$. The pattern was interesting because it appeared as the mean number of interactions increased, a disproportionate increase likes and comments were being directed towards information and resources, while the limited interactions among low and medium users were constrained to the categories around social interaction. The pattern of responses to the most common humor and academic reading posts was consistent across groups, suggesting that everyone was similarly interested or not, respectively, in engaging posts that did not have an immediate social context.

\section{Discussion}

The interest in using Facebook for academic purposes is increasing (Lim \& Richardson, 2016), and the context investigated here, while extra-curricular, is an example of a faculty-led use of Facebook to foster student engagement. The patterns observed were largely consistent with previous findings that the network is best suited for providing social connections and enjoyment (Sledgianowski \& Kulviwat, 2009; Jong, Lai, Hsia, Lin, \& Liao, 2014; Sharma, Joshi, \& Sharma, 2016). Posts that required the reading of external content (links, readings, and video) had fewer interactions, while posts that were self-contained with humorous content, images, or were peer-related received the most. It was also probable that the super users in this group were super users of Facebook overall, because greater personal use is associated with increased academic uses of Facebook (Mazman \& Usluel, 2010). However, the implications are not necessarily that Facebook was a poor venue academically. Indeed, there is clear evidence of interactions that would be valuable to educators and administrators. Research has identified that a number of students perform well enough to sustain enrollment, but still drop out from college because of a perceived lack of belonging, particularly with peers (Strauss \& Volkwein, 2004). Also, the number of college-based Facebook friends have been associated with student retention, particularly for minorities and international students (Gray, Vitak, Easton, \& Ellison, 2013). We contend this study provides evidence how an academic Facebook group supported and even favored interactions that relate to social integration. While it cannot be claimed that graduate students in this study were in anyway retained by their participation this Facebook group, it is clear that the network was most active when facilitating interactions that related to academic social connections. Given its wide adoption by the students, Facebook offered an easy-to-use opportunity for the department to connect with and among its students and alumni not afforded by other methods.

\section{Conclusion}

This study contributed to the research on SNSs, particularly the use of Facebook in higher education by examining its contextual usage in an active group. A major limitation is that this study examined a single case. It is possible other academic groups would interact differently with their content. Furthermore, the findings do not suggest that academic readings are not useful or beneficial to group members, but simply that they did not generate observable interactions. Taking that in to account, the faculty administrator of the group might be representative of other professors who hope to build their relationships among their students and alumni both personally and professionally. While these results are not promising for faculty who might consider Facebook as a formal channel of instruction, they should find encouragement that it can function as a space for voluntary student engagement around their social academic contexts. The purposes of 
this study notwithstanding, it was one of the faculty administrator's goals to build and maintain a network of students and alumni in their department. There is evidence from the analysis of interaction data that the Facebook was most successful in that regard. For this group, Facebook served as a powerful and, indeed, social network.

\section{Authors' contributions}

DMR designed the study, researched prior literature, performed inductive coding, and contributed and edited the manuscript. MR assisted in the design of the study, researched prior literature, performed inductive coding, performed the statistical analyses, and drafted the manuscript. KM and $\mathrm{SH}$ collected and tallied the raw data for analysis. All authors read and approved the final manuscript.

\section{Competing interests}

The authors declare they have no competing interests.

\section{Publisher's Note}

Springer Nature remains neutral with regard to jurisdictional claims in published maps and institutional affiliations.

Received: 16 January 2017 Accepted: 3 May 2017

Published online: 12 June 2017

\section{References}

Arthur, C. (2006). What is the 1\% rule? The Guardian, Retrieved May 23, 2016 from http://www.theguardian.com/ technology/2006/jul/20/guardianweeklytechnologysection2.

Bowman, N. D., \& Akcaoglu, M. (2014). "I see smart people!": Using Facebook to supplement cognitive and affective learning in the university mass lecture. The Internet and Higher Education, 23, 1-8.

Boyd, D., \& Ellison, N. (2010). Social network sites: definition, history, and scholarship. IEEE Engineering Management Review, 3(38), 16-31.

Bryman, A. (2001). Social research methods. Oxford: Oxford University Press.

Bugeja, M. J. (2006). Facing the Facebook. Chronicle of Higher Education, 52(21), C1-C4.

Cuesta, M., Eklund, M., Rydin, I., \& Witt, A.-K. (2015). Using Facebook as a co-learning community in higher education. Learning, Media and Technology, 41(1), 1-18.

Cvijikj, I. P., \& Michahelles, F. (2013). Online engagement factors on Facebook brand pages. Social Network Analysis and Mining, 3(4), 843-861.

Davis, F. D. (1989). Perceived usefulness, perceived ease of use, and user acceptance of information technology. MIS Quarterly, 13(3), 319-339.

Davis, F. D., Bagozzi, R. P., \& Warshaw, P. R. (1989). User acceptance of computer technology: a comparison of two theoretical models. Management Science, 35(8), 982-1003.

Davis, F. D. (1985). A technology acceptance model for empirically testing new end-user systems: theory and results. Cambridge: Unpublished doctoral dissertation, Massachusetts Institute of Technology.

Echenique, E. G., Molías, L. M., \& Bullen, M. (2015). Students in higher education: social and academic uses of digital technology. Revista de Universidad y Sociedad del Conocimiento, 12(1), 25-37.

Facebook (2016). Company Info | Facebook Newsroom. Retrieved March 21, 2016, from http://newsroom.fb.com/ company-info/.

Gettman, H. J., \& Cortijo, V. (2015). "Leave me and my Facebook alone!" Understanding college students' relationship with Facebook and its use for academic purposes. International Journal for the Scholarship of Teaching and Learning, 9(1), Article 8.

Gray, R., Vitak, J., Easton, E. W., \& Ellison, N. B. (2013). Examining social adjustment to college in the age of social media: factors influencing successful transitions and persistence. Computers \& Education, 67, 193-207.

Greenwood, S., Perrin, A., \& Duggan, M. (2016). Social media update 2016. Retrieved from http://www.pewinternet.org/ 2016/11/11/social-media-update-2016/.

Hew, K. F. (2011). Students' and teachers' use of Facebook. Computers in Human Behavior, 27, 662-676.

Jong, B.-S., Lai, C.-H., Hsia, Y.-T., Lin, T.-W., \& Liao, Y.-S. (2014). An exploration of the potential educational value of Facebook. Computers in Human Behavior, 32, 201-211.

Junco, R. (2012). The relationship between frequency of Facebook use, participation in Facebook activities, and student engagement. Computers \& Education, 58, 162-171.

Kincaid, J. (2009). Facebook activates "like" button; FriendFeed tires of sincere flattery. TechCrunch. Retrieved from http://techcrunch.com/2009/02/09/facebook-activates-like-button-friendfeed-tires-of-sincere-flattery/.

Kirschner, P. A., \& Karpinski, A. C. (2010). Facebook ${ }^{\circledR}$ and academic performance. Online Interactivity: Role of Technology in Behavior Change, 26(6), 1237-1245.

Lim, J., \& Richardson, J. C. (2016). Exploring the effects of students' social networking experience on social presence and perceptions of using SNSs for educational purposes. The Internet and Higher Education, 29, 31-39.

Madge, C., Meek, J., Wellens, J., \& Hooley, T. (2009). Facebook, social integration and informal learning at university: 'It is more for socialising and talking to friends about work than for actually doing work'. Learning, Media and Technology, 34(2), 141-155.

Manca, S., \& Ranieri, M. (2013). Is it a tool suitable for learning? A critical review of the literature on Facebook as a technology-enhanced learning environment. Journal of Computer Assisted Learning, 29(6), 487-504.

Mason, R. (2006). Learning technologies for adult continuing education. Studies in Continuing Education, 28(2), 121-133.

Mazman, S. G., \& Usluel, Y. K. (2010). Modeling educational usage of Facebook. Computers \& Education, 55, 444-453. 
Roblyer, M., McDaniel, M., Webb, M., Herman, J., \& Witty, J. V. (2010). Findings on Facebook in higher education: a comparison of college faculty and student uses and perceptions of social networking sites. The Internet and Higher Education, 13, 134-140.

Sarapin, S. H., \& Morris, P. L. (2015). Faculty and Facebook friending: Instructor-student online social communication from the professor's perspective. The Internet and Higher Education, 27, 14-23.

Saw, G., Abbott, W., Donaghey, J., \& McDonald, C. (2013). Social media for international students-it's not all about Facebook. Library Management, 34(3), 156-174.

Selwyn, N. (2007). Web 2.0 applications as alternative environments for informal learning-a critical review. In CERI-KERIS International Expert Meeting on ICT and Educational Performance (pp. 16-17). Cheju Island: Organization for Economic Co-Operation and Development.

Sharma, S. K., Joshi, A., \& Sharma, H. (2016). A multi-analytical approach to predict the Facebook usage in higher education. Computers in Human Behavior, 55, 340-353.

Siemens, G., \& Weller, M. (2011). Monograph "the impact of social networks on teaching and learning". introduction: higher education and the promises and perils of social networks. RUSC. Universities and Knowledge Society Journal, $8(1), 156-326$

Sledgianowski, D., \& Kulviwat, S. (2009). Using social network sites: the effects of playfulness, critical mass and trust in a hedonic context. Journal of Computer Information Systems, 49(4), 74-83.

Strauss, L. C., \& Volkwein, J. F. (2004). Predictors of student commitment at two-year and four-year institutions. Journal of Higher Education, 75(2), 203-227.

Thomas, D. R. (2006). A general inductive approach for analyzing qualitative evaluation data. American Journal of Evaluation, 27, 219-236.

Tinto, V. (1975). Dropout from higher education: a theoretical synthesis of recent research. Review of Educational Research, 45(1), 89-125.

Valerio, G., Herrera-Murillo, D. J., Villanueva-Puente, F., Herrera-Murillo, N., \& del Carmen Rodríguez-Martínez, M. (2015). The relationship between post formats and digital engagement: a study of the Facebook pages of Mexican universities. Revista de Universidad y Sociedad del Conocimiento, 12(1), 50-63.

Van der Heijden, H. (2004). User acceptance of hedonic information systems. MIS Quarterly, 28, 695-704.

van Mierlo, T. (2014). The 1\% rule in four digital health social networks: an observational study. Journal of Medical Internet Research, 16(2), e33.

Venkatesh, V., \& Davis, F. D. (2000). A theoretical extension of the technology acceptance model: four longitudinal field studies. Management Science, 46(2), 186-204.

Wilson, R. E., Gosling, S. D., \& Graham, L. T. (2012). A review of Facebook research in the social sciences. Perspectives on Psychological Science, 7(3), 203-220.

\section{Submit your manuscript to a SpringerOpen ${ }^{\circ}$ journal and benefit from:}

- Convenient online submission

- Rigorous peer review

- Immediate publication on acceptance

- Open access: articles freely available online

- High visibility within the field

- Retaining the copyright to your article 